
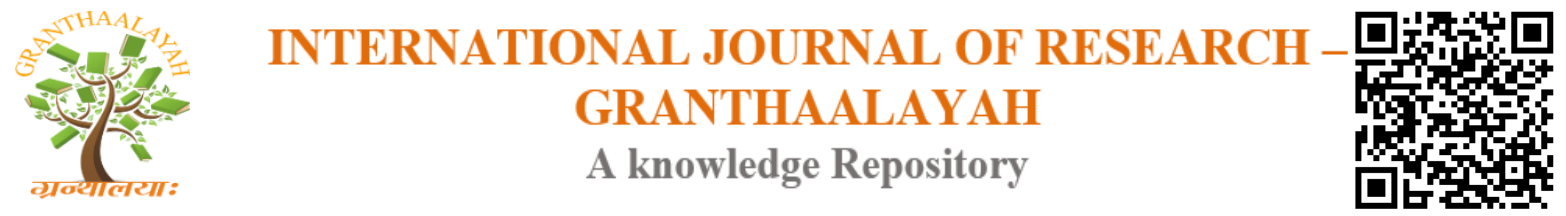

Science

\title{
QUALITY CONTROL CONSIDERATION: EFFICIENT REAL-TIME WATER MONITORING UTILIZING MULTI-SENSORS AND ICT CONCEPTS
}

\author{
T. Srour ${ }^{* 1}$, Ayman Haggag ${ }^{2}$, Mohsen A. M. El-Bendary ${ }^{3}$, Ibrahim Saber ${ }^{4}$, A. E. Abou \\ Elazm ${ }^{5}$ \\ *1,2,3 Department of Electronics Technology, Faculty of Industrial Education, Helwan \\ University, Egypt \\ ${ }^{4}$ Faculty of Education - Helwan University, Egypt \\ ${ }^{5}$ Department of Electronics, Faculty of Electronics Engineering, Menofia University, Egypt
}

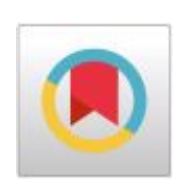

\begin{abstract}
Design efficient an interactive system for water pollution monitoring and quality control is proposed in this paper utilizing different sensors and employing Information Communication Technology (ICT). The presented system is built based on the $\mathrm{pH}$ and temperature water parameters. The system consists of sensors, Arduino controller and designed Graphical User Interface (GUI). GUI is designed to display the parameters values and control option. The operator can control the parameters values through operating control systems by a set of control switches in GUI. For example, the result of $\mathrm{pH}$ parameter during the monitoring $=7.06$, while after operating the control system the $\mathrm{pH}$ parameter $=10.16$. This result shows the ability of the system to monitor and control of water parameters. Different water parameters and properties are discussed in this paper also.
\end{abstract}

Keywords: Water Parameters; Monitoring Water; Traditional Method; Gab-Time; Real-Time; ICT.

Cite This Article: T. Srour, Ayman Haggag, Mohsen A. M. El-Bendary, Ibrahim Saber, and A. E. Abou Elazm. (2018). "QUALITY CONTROL CONSIDERATION: EFFICIENT REAL-TIME WATER MONITORING UTILIZING MULTI-SENSORS AND ICT CONCEPTS." International Journal of Research - Granthaalayah, 6(10), 240-255. https://doi.org/10.29121/granthaalayah.v6.i10.2018.1191.

\section{Introduction}

Water is the most important source of life on Earth and therefore we must keep it cleans. It is known that water consists of two hydrogen atoms and an oxygen atom. Water also exists in three forms, liquid, solid and gaseous. Natural water does not exist purely due to the factors it is exposed to it, as it is affected by air, sand and rocks. As a result of all these factors, water is contaminated with chemical, physical and biological composites. Each of these properties contains many 
parameters that must be monitored, as each of them must be between specific values, according to international water quality organizations. Each parameter has specific acceptable values according to the application in which water will be used for, whether for drinking, agriculture and industry. Therefore, we must pay attention to monitoring the quality of water parameters and keep them within their standard values. [1,2]

The use of Information Communication Technology (ICT) covers sending and receiving all types of information. ICT is the basic boost for the economy and the moving force for social shift in these days. With the use of ICT, distance is not an obstacle when it relates to information, and access to information became as easy as possible. ICT has become commonly used in our daily lives as it provides all the technical means used in information processing and communication facilities utilizing computers, communications lines and programs. Various applications of ICT include Internet services, e-learning, e-banking. Each of these applications is used for information exchange and processing. The information exchange may be wired or wireless system according to the system needs [3]. There are many researchers working on ICT applications in monitoring systems through their research. Different applications of ICT have been presented in this research work [4-7].

In H. Kobayashi et al. [4], a system based on ICT is used to monitor the conditions of elder persons in a health care center through the construction of a system that monitors their health status by using group of sensors that collect data such as blood pressure, breathing and pulse rate. These sensors collect the data and send to the monitoring station. In the event of an emergency, an alert is sent to the person responsible for monitoring so necessary procedures are taken. This paper also indicates some of the problems that may challenge the system during its operation and how to overcome them. In Y. Liu et al. [5], a system based on ICT is used in monitoring the behavior of drivers while driving through a group of sensors that work on collecting data and sending it to a wireless monitoring center through the $3 \mathrm{G}$ wireless network. The monitoring center analyzes the data and determines the behavior of the driver and then sends information to the authority responsible for improving the safety of drivers. In Y. Jen et al. [6], a system based on ICT is used to development emergency management in railway stations. ICT helps to provide real-time critical information and thus facilitates rapid response and decision-making processes. ICT is used to improve the efficiency of services within railway stations, leading to customer satisfaction about the services provided. The railway stations are dealing with big data such as train time tables, Ticket booking data, Road status data, etc. ICT provide all these data high speed, accuracy and without errors, thus leading to increasing the efficiency of railway stations. In Y. Lin et al. [7], ICT is used in environmental monitoring. This paper presents the possibility of using ICT to monitor the agricultural environment in order to increase agricultural crops through monitoring the risks of pollution in the surrounding area as well as monitoring the state of soil and water used in irrigation. This system works on exchanging information gathered from sensors that monitor the state of the agricultural environment in real-time and according to this information. The user takes the correct decision.

In the presented research paper, the proposed system based on ICT is presented to be used in environmental monitoring, to monitor the quality of water. A system will build to monitor water parameters such as $\mathrm{pH}$ and water temperature as well as controlling these parameters through the system. ICT helps reduce human errors in measurements, reduce manpower and obtain accurate 
results that reflect the state of water in real time without any time gaps. A group of sensors that monitor the state of water and send information that is measured to the main monitoring center. The main monitoring center analyzes the information and accordingly makes suitable decisions to regulate the status of water through the operation of control systems to control its parameters.

Figure 1 shows the way which used ICT in the monitoring. The monitoring center connect to the parameters which will monitor through interface transmit the information which reflect about the parameters which monitored.
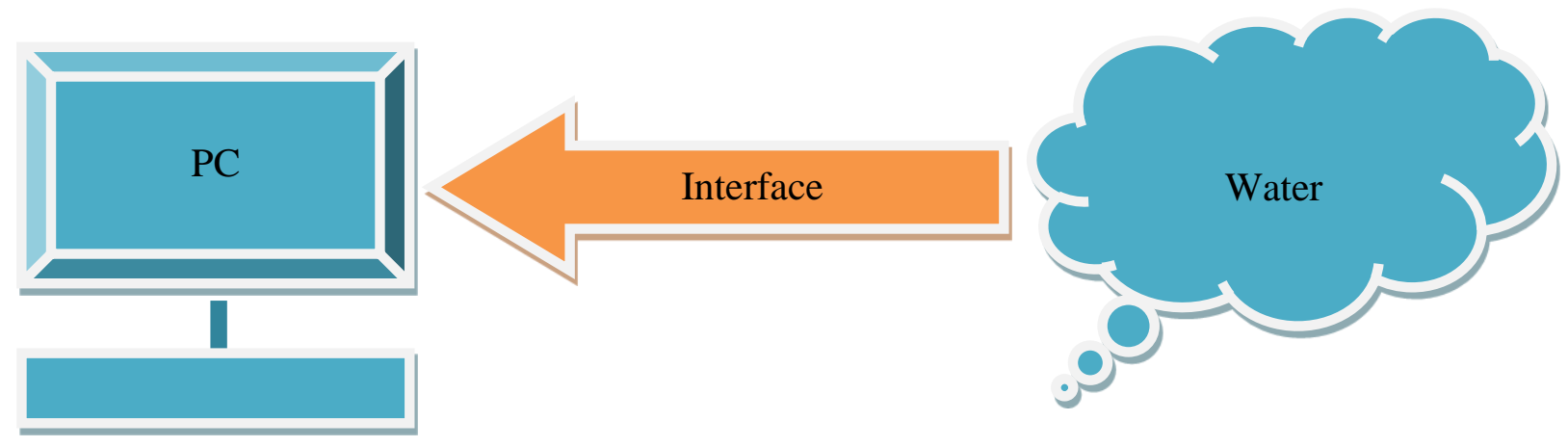

Figure 1: Water monitoring system

The rest of this paper is organized as follows; in section 2, water monitoring principle is presented. The previous related work is presented in section 3. The proposed system is described in section 4. In section 5, experimental results and analysis are discusses. Finally, the paper conclusion is presented in section 6 .

\section{Water Monitoring}

Before talking about the traditional methods used in Water treatment station, we will talk about some water properties and parameters. Water properties are divided into three categories: - [2]

\section{Chemical Properties}

Chemical properties tend to be more specific in nature than physical variables. It is also better in assessing the characteristics of the sample taken from the water. Chemical parameters are related to a group of chemicals whose values significantly affect the water sample and to a large extent to determine which of the applications Water can be used in it. These chemical parameters include Hardness, Dissolved oxygen, Oxygen demand, Nitrogen etc.

\section{Physical Properties}

Physical properties are a group of simple characteristics that can be discovered by non-specialist as temperature, taste, odor, turbidity and other elements.

\section{Biological Properties}

The biological properties are among the most important characteristics that must be taken into account, especially in the wastewater, which must be processed for use again, because it contains many microorganisms that may carry many diseases that affect human health. 
All these properties are very important in water monitoring. Details about these properties are classified based on its parameters as displayed in Figure 2.

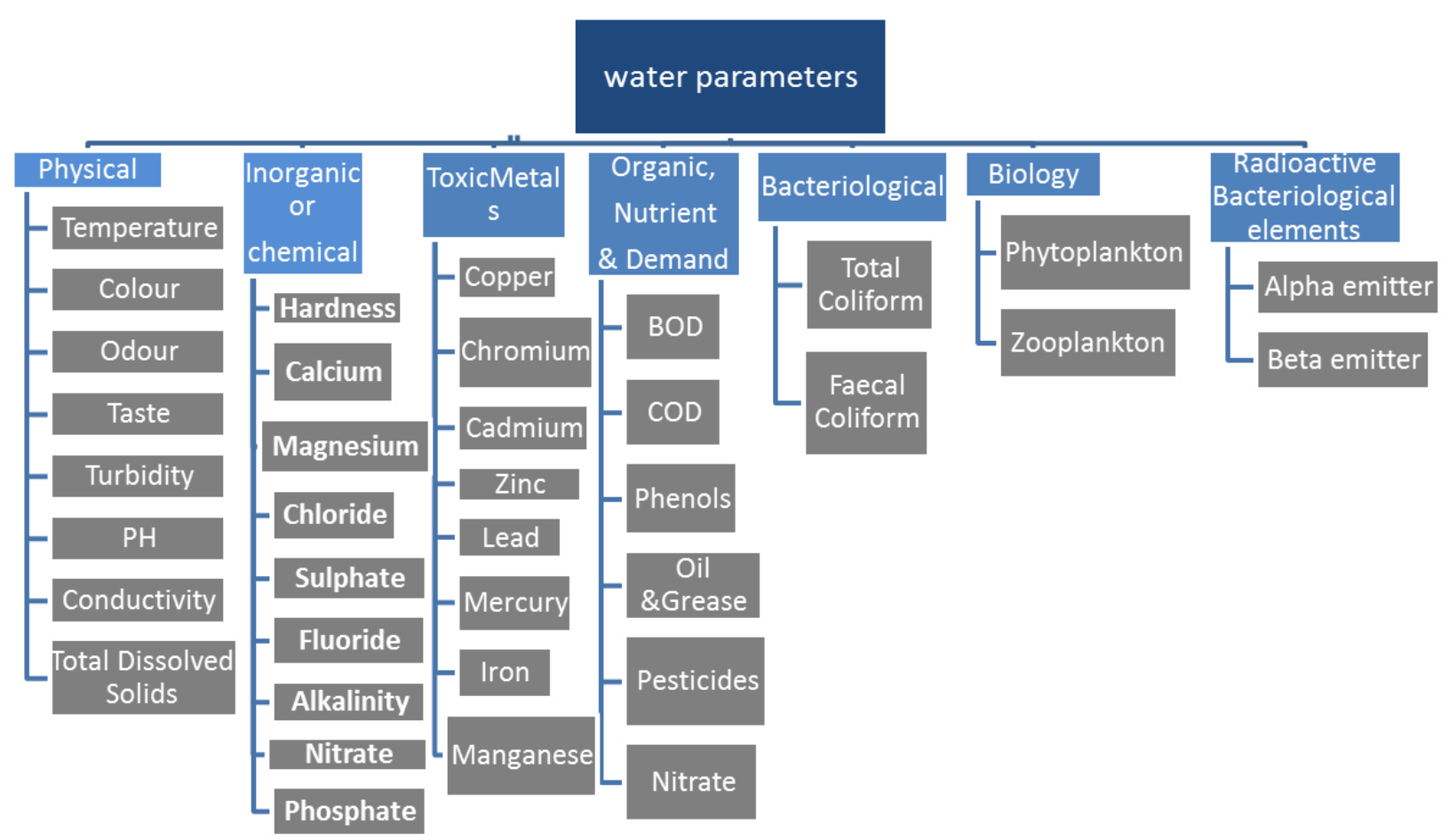

Figure 2: Different water parameters classifications

All these parameters have specific values that are different from one application to another. So we must know these values when performing water monitoring in a specific application. Among these applications is the monitoring of drinking water.

Through a field visit to one of the water treatment stations in Egypt, we found that certain parameters need to be monitored every hour. Other parameters need to be monitored weekly and other monthly. Monitoring in this station implemented traditional method where samples from water are taken then analyzed in the laboratory. The disadvantage of this method is that the result does not indicate the real time state of the water because the gap time between taking samples and analyses in the laboratory. In this gap time, changes may occur in the water parameters that lead to inaccurate results. So we will design our system is able to monitor and control water parameters in real time. In the proposal design will monitor and control values both $\mathrm{pH}$ and temperature parameters.

\section{The pH Parameter}

$\mathrm{pH}$ is defined as the negative logarithm of the hydrogen ion concentration, where $\mathrm{pH}$ is the power of hydrogen. The $\mathrm{pH}$ value is expressed as the ratio of hydroxide ion concentration, $[\mathrm{H}+]$ to $[\mathrm{OH}-$ ]. Therefore, if the $[\mathrm{H}+]$ is greater than $[\mathrm{OH}-]$, the solution is acidic. Oppositely, if the [OH-] is greater than the $[\mathrm{H}+]$, the solution is basic. At a $\mathrm{pH}$ of 7 , the ratio of $[\mathrm{H}+]$ to $\left[\mathrm{OH}_{-}\right]$is equal and, therefore, the solution is neutral. 
There are many ways to measure $\mathrm{pH}$, such as using indicators or $\mathrm{pH}$ electrode sensor. Indicators are specific materials used to measure $\mathrm{pH}$ through colors where the color of the material changes when $\mathrm{pH}$ value changes. Each $\mathrm{pH}$ value corresponds to a different color. $\mathrm{pH}$ values range from 0 to 14 [9]. pH electrode sensor will be used in our methodology.

\section{The Temperature Parameter}

Water temperature is an important parameter that must be monitored because it affects other parameters such as $\mathrm{pH}$ and may lead to incorrect results. High temperatures accelerate the corrosion of the $\mathrm{pH}$ electrode and may change the millivolt output of the $\mathrm{pH}$ electrode. If the temperature is very high, it may boil the fill solution while very low temperature may freeze it, causing the electrode tip to break or crack.

Very high temperatures may also induce different temperature for at the interior and exterior of the $\mathrm{pH}$ electrode [10]. Variations in temperature may degrade the accuracy and speed of response of the Electrode. A Temperature Coefficient needs to be considered to compensate for the effects on the material being measured by the sensor, and must be included in the calibration or samples taken [11].

\section{Previous Related Work}

A large number of researchers are interested in monitoring water parameters in many fields where it critical to monitor and control those parameters. In an attempt to overcome the inaccurate results that occur from use traditional methods in water monitoring. In this section, we will present a number of ideas presented by a number of researchers interested in this field. In S. Priya et al. [12], they did not talk about monitoring water but talked about monitoring industrial parameters such as temperature, water level and pressure. This paper designed a system that operates on monitoring and controlling industrial parameters to reduce manpower and also to reduce the mistakes which may occur through manual monitoring. In Ö. Çetinkaya et al. [13], they measured water level and water temperature in a tank. This paper used potentiometer to measure the water level and the sensor $\operatorname{lm} 35$ to measure temperature where the controller was PIC16f877 and the results were displayed on the LCD screen. In D. Jain et al. [14], this study addressed the issue of monitoring water through an electronic system to achieve accurate results. This system is Adjustable for use in other liquids monitoring. The proposed monitoring system is given in Figure 3.

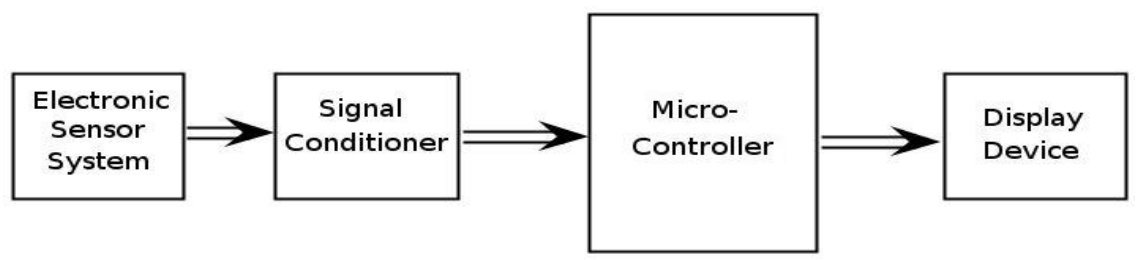

Figure 3: Block Diagram of system

In M. Pradeepkumar et al. [15], the system operates on water monitoring in real time. Figure 4 shows the proposed system block diagram. This system monitors several parameters such as $\mathrm{pH}$, temperature and turbidity through using a sensor for each parameter. Sensors send data to Arduino then to the monitoring center. The system monitors the parameters values; it sends a message to the manager of the mobile terminal if the parameters value increases more than the threshold. The 
suitable action according to these reading is taken by the administration of the fixed monitoring station. In A. Srivatsava et al. [16], a system is used to monitor the water through several sensors and a raspberry pi and the data are uploaded to internet for cloud storage or display on the display unit. Motor connected to the processor for pumping purpose. The presented system contents in this paper are given in Figure 5.

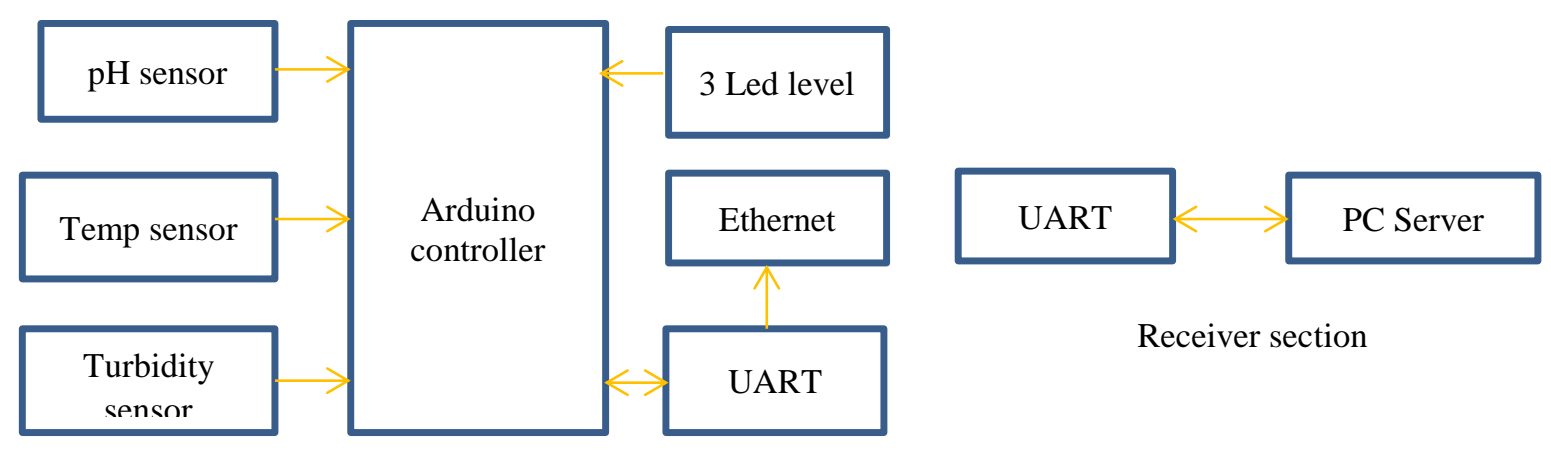

Transmitter section

Figure 4: Block Diagram of system

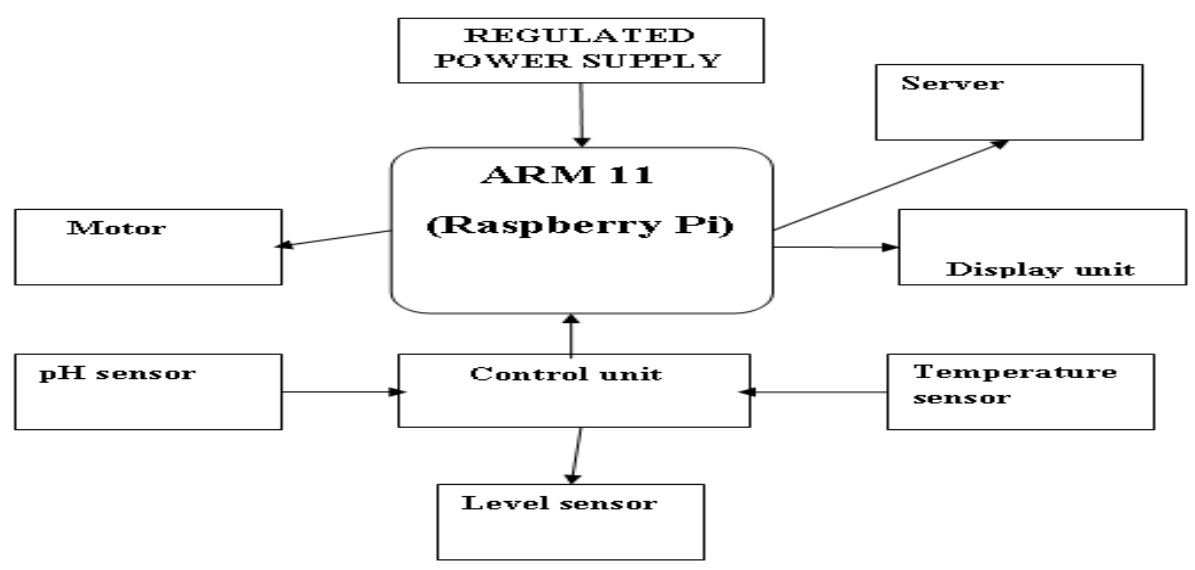

Figure 5: Block diagram of system

\section{The Proposed Water Monitoring Technique}

In this section, we will present the components of the system that mainly consists of two parts, hardware and software.

\subsection{Hardware Design}

The hardware system consists of two parts the sensing unit and the control unit.

\subsubsection{The Sensing Unit}

The sensing unit is responsible for reading parameters within water through sensors. There are two sensors, $\mathrm{pH}$ sensor and temperature sensor. 


\section{Ph Sensor}

$\mathrm{pH}$ electrode sensor consists of two parts, the measuring electrode and the reference electrode. Figure 6 shows the principle of $\mathrm{pH}$ measurement. The $\mathrm{pH}$ measurement is the difference between the two electrodes. The mathematical expression is given as follows:

$\mathrm{E}=\mathrm{Em}-\mathrm{Er}$

Where:

$\mathrm{Em}=$ the electrode potential of the measuring electrode

$\mathrm{Er}=$ the electrode potential of the reference electrode [9]

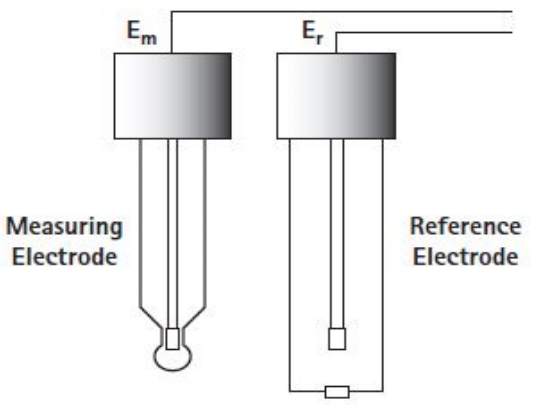

Figure 6: Mechanism work of pH electrode

Figure 7 shows $\mathrm{pH}$ sensor and the specifications of the $\mathrm{pH}$ sensor are discussed in [17].

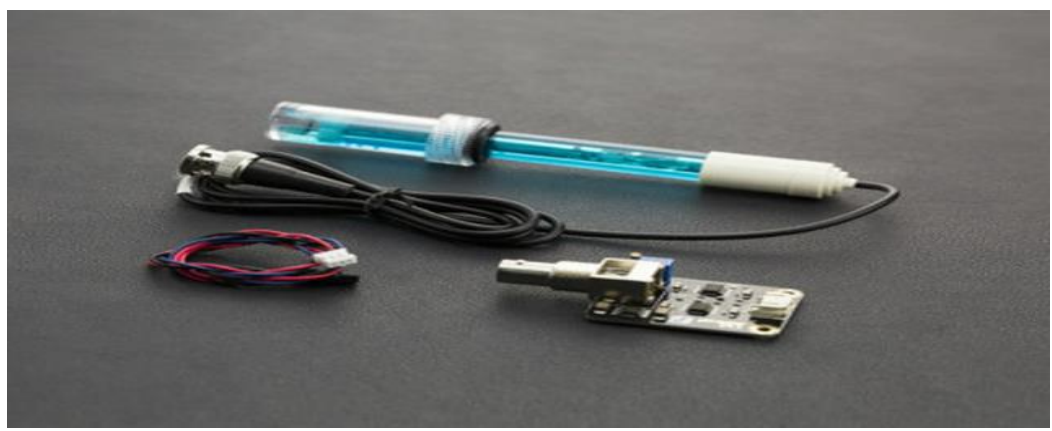

Figure 7: the used $\mathrm{pH}$ sensor

\section{Temperature Sensor}

This sensor is used to measure water temperature and is put inside water. It is able convert the temperature to voltage. This voltage indicates water temperature. It is shown in Figure 8 and the specifications of the sensor are discussed in [18].

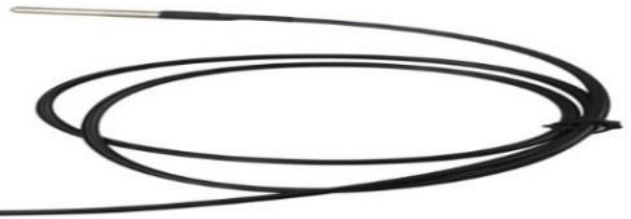

Figure 8: Used sensor of water temperature 


\subsubsection{The Control Unit}

This unit is responsible for processing the data which passes through cable from the sensing unit. This received data is processed by the designed the algorithm stored in the control unit. In this system, the control unit is Arduino Uno. The Arduino is a cheap controller used to build interactive projects, such as GPS tracking systems, remote-controlled robots, and electronic game [19]. Arduino hardware and software is easy to use. There are different types of Arduino boards. The common board is the Uno board Figure 9 gives the Uno board, which is utilized in the proposed system in this research work and the Specifications of Uno board are discussed in [20].
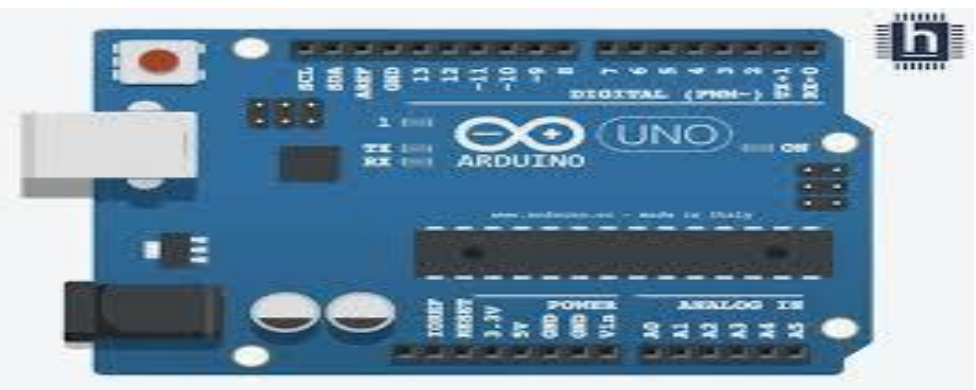

Figure 9: used Arduino Uno board

The proposed water monitoring and quality control system block diagram is given in Figure 10. This presented system can monitor the water parameters in real-time. Also, it is an interactive system, the water parameters can be changed by specific algorithm through the feedback path from the controller to the monitored water. The details of the proposed system contents and its mechanism work are cleared in Figure 11 and Figure 12 displays the practical system.

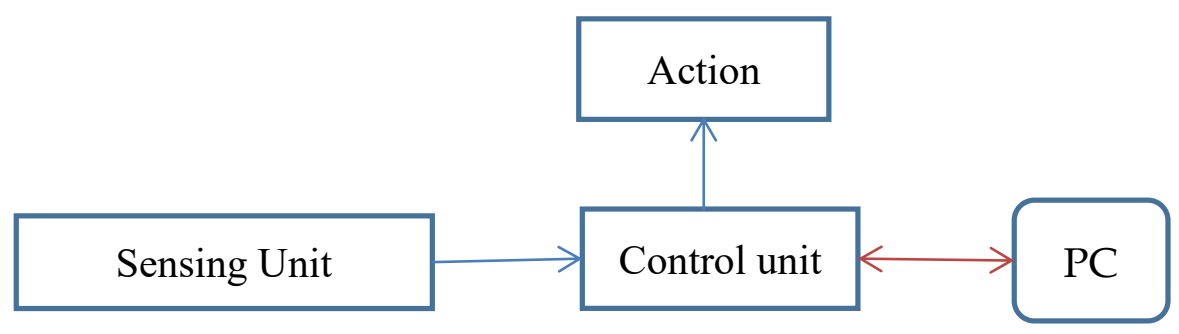

Figure 10: Block diagram of the proposed water pollution monitoring

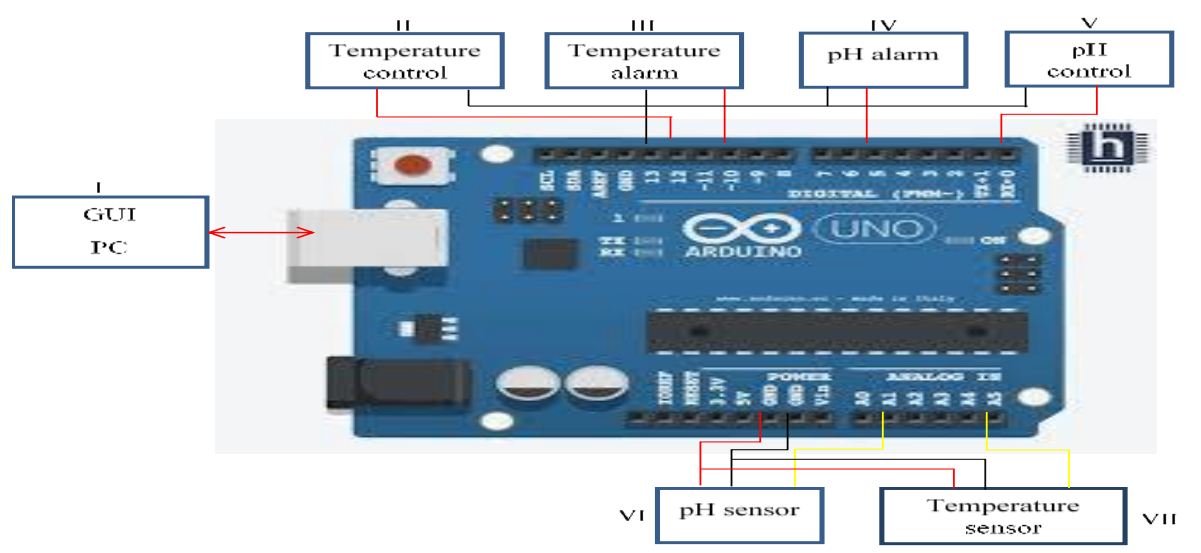

Figure 11: Proposed system contents and connection diagram description 


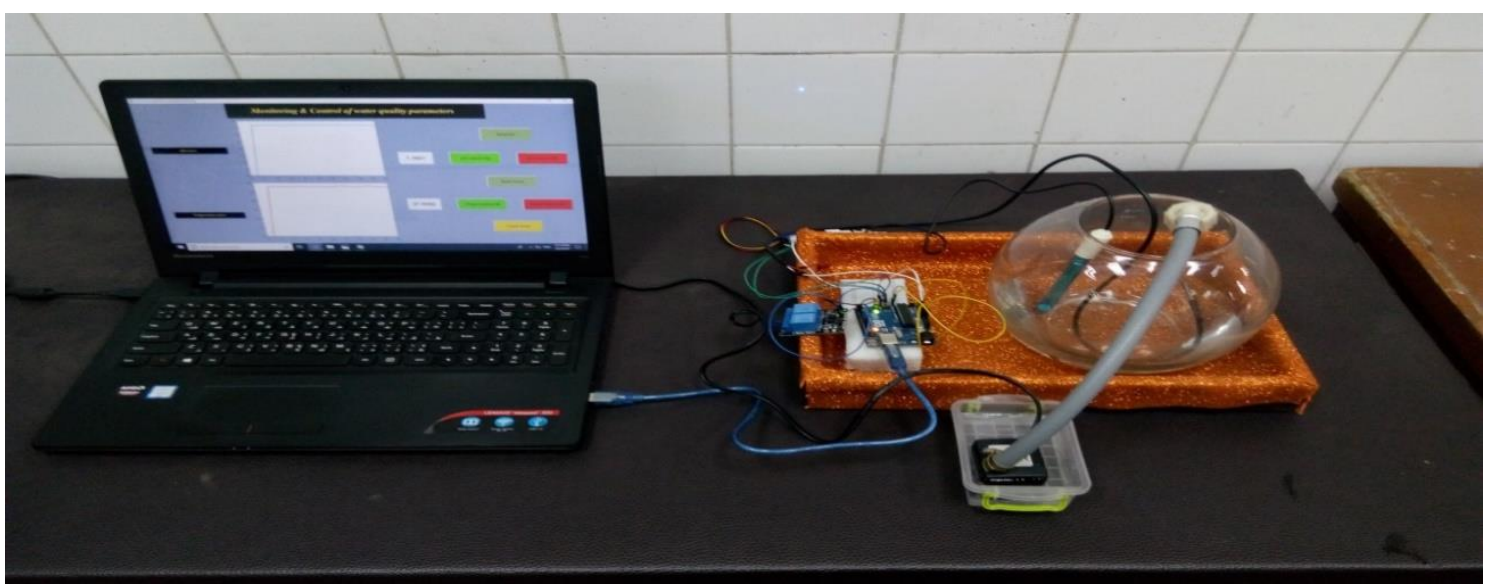

Figure 12: the practical system

\subsection{Software Design}

The software is a graphic user interface (GUI) on a Matlab program. The GUI screen will use by the user to know the information about water parameters $(\mathrm{pH}$, temperature). The user will be able to control water parameters through switch group used to turn the control system on/off to adjust water parameters. These GUI will display in the Experimental Results section.

\subsection{Operation Mechanism}

In this section, the mechanism of the proposed system operation is described. When we press on the read sensors switch using the GUI. The sensors start to read. The sensors pass the electrical signals to the control unit. The control unit starts to process the signals according to the algorithm then passes the data to the GUI through the interface cable. The GUI presents the data which indicates the parameters value on screen in the form of curves and in numeric values. The user monitors the data through curves and numeric values as long as reading is within normal values. When values became outside normal values, the user is able to control parameters values through the control switch group which operates the control system to increase or decrease parameters values according to status of parameters. The control system is also capable of working automatically when values reach a risky value through the algorithm stored on the control unit. Figure 16 shows flowchart of the proposed work operation. 


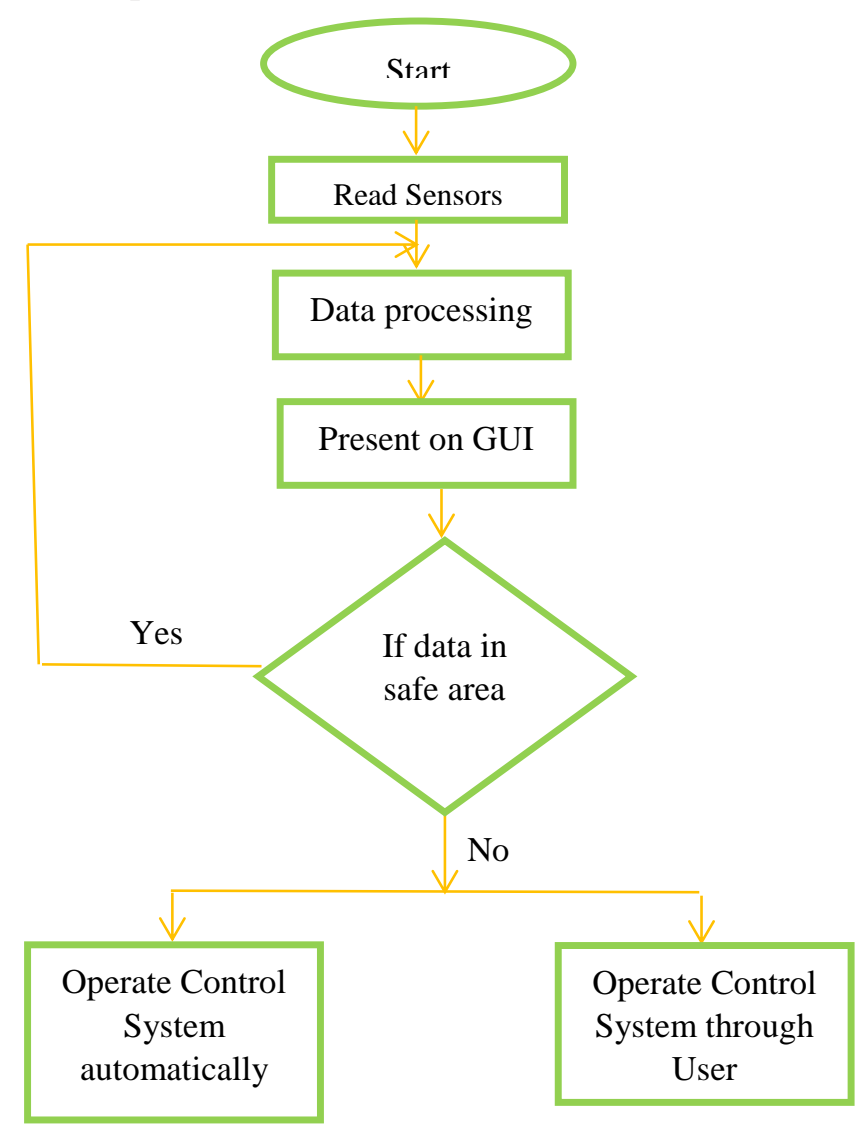

Figure 16: Proposed technique operation flow-chart

\section{Experimental Results and Analysis}

In this section, we show results obtained through practical implementation of our system.

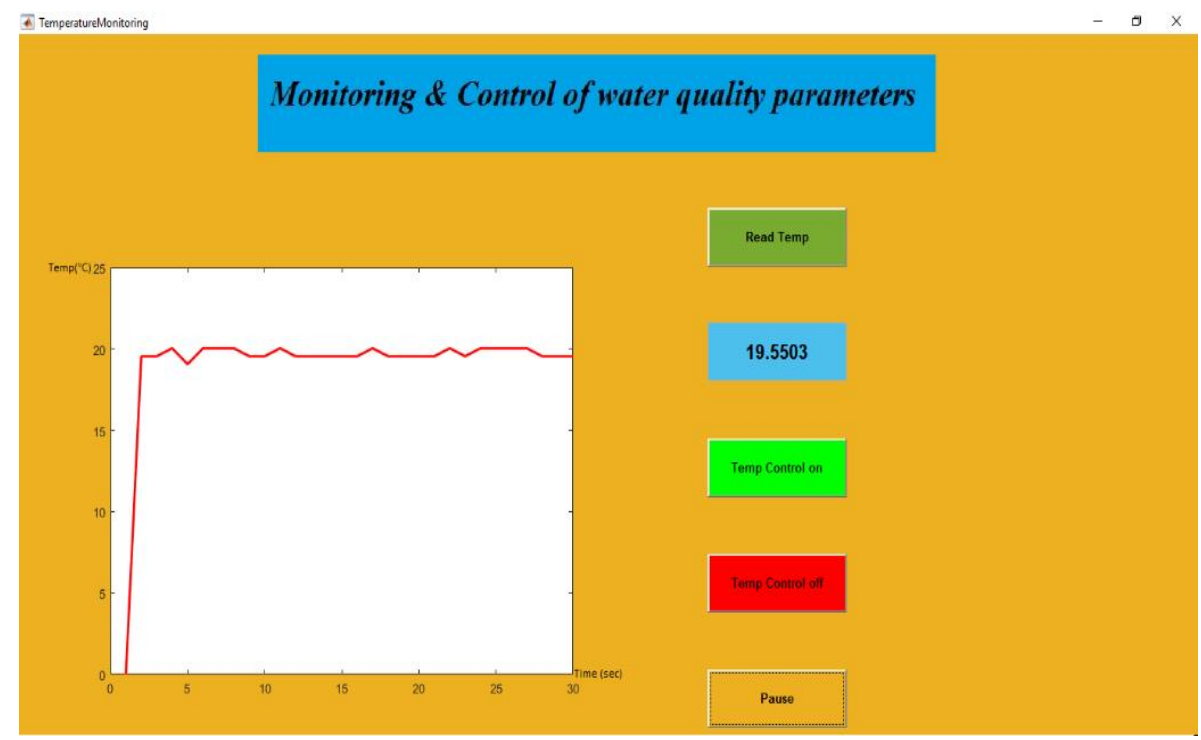

Figure 17: GUI Monitoring Temperature 


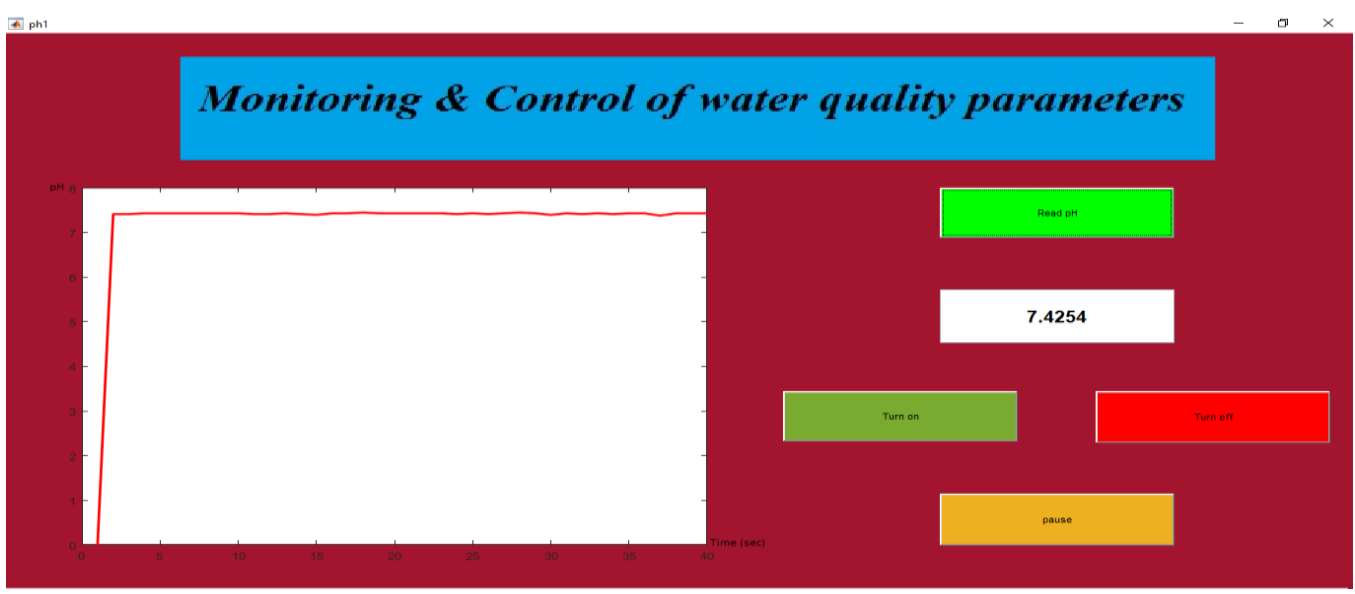

Figure 18: GUI Monitoring $\mathrm{pH}$

The previous two Figures 17, 18 show the results of monitoring the same water sample inside a tank where the temperature was monitored and the results were as displayed in the figure 17 where temperature $=19.55^{\circ} \mathrm{C}$. Then the $\mathrm{pH}$ was monitored and the results were as displayed in the figure 18 where $\mathrm{pH}=7.42$. The change of these values can also be controlled by the control switches which are shown in the GUI to turn the switch ON and OFF to control the system.

The following figure 19 show the result of control in $\mathrm{pH}$ :

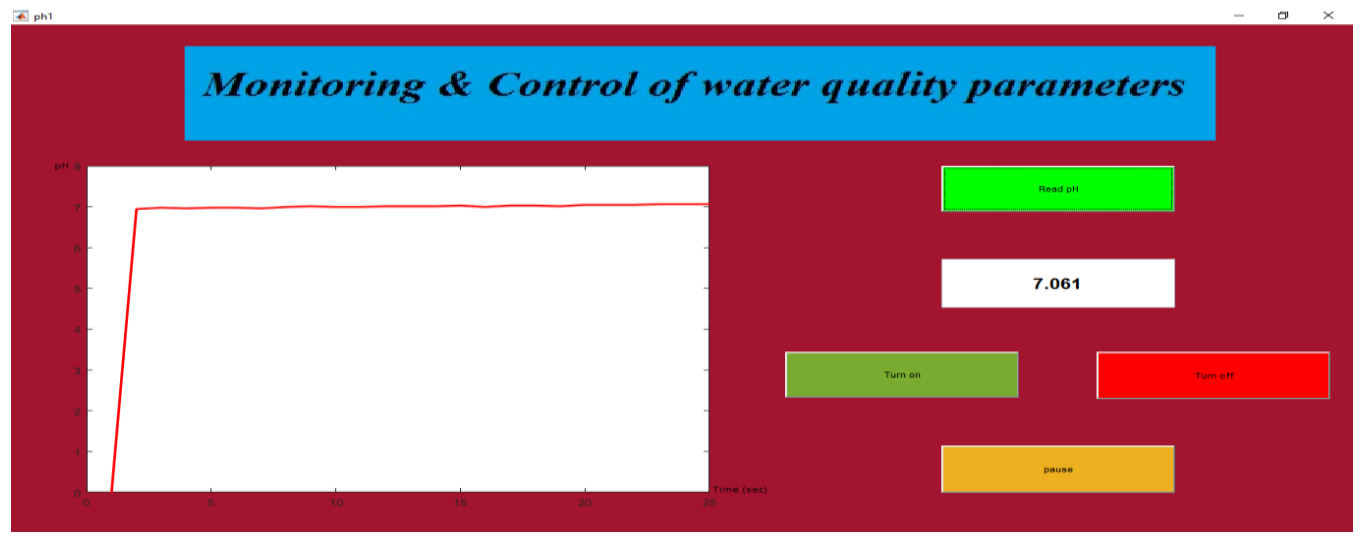

A

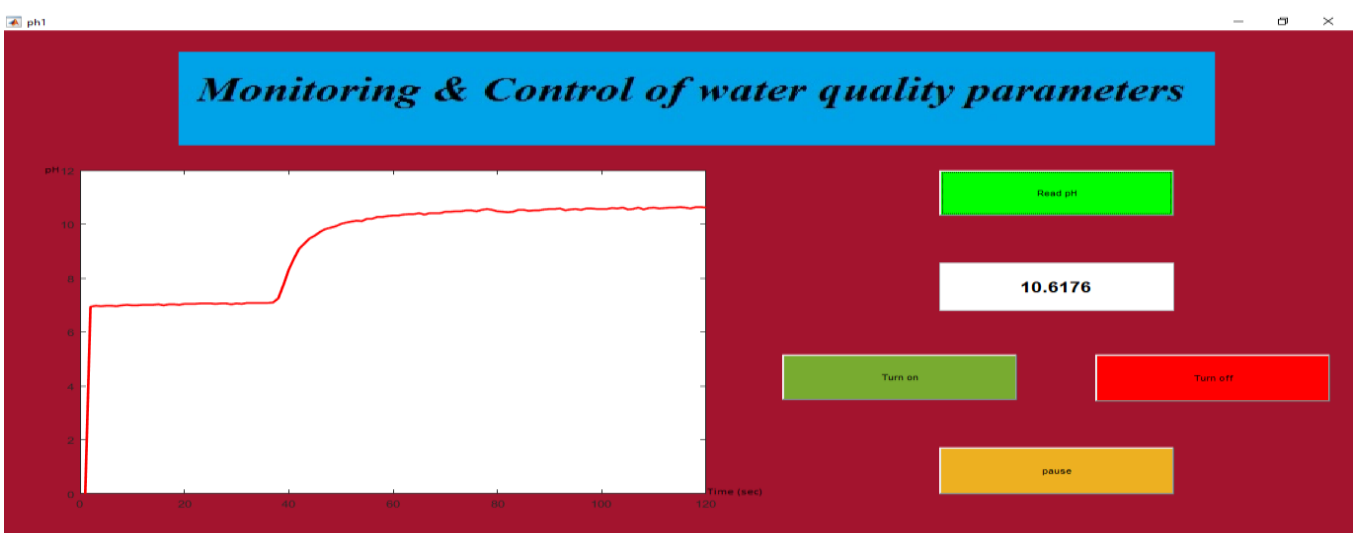

B

Figure 19: GUI Monitoring \& control of $\mathrm{pH}$ 
Figures 19-A, 19-B show the results of monitoring and controlling in $\mathrm{pH}$ parameter. Figure 19-A shows the reading example of $\mathrm{pH}$ parameter in a sample of water and the $\mathrm{pH}$ reading was $=7.06$. Through press on switch $\mathrm{pH}$ control $\mathrm{ON}$ the control system operates and add material in water through it the $\mathrm{pH}$ value increased and the $\mathrm{pH}$ reading became $=10.16$ as in figure $19-\mathrm{B}$. This result confirms that the system is able to monitor and control the $\mathrm{pH}$ parameter.

The following figures show the results of $\mathrm{pH}$ and temperature together.

These results for three water samples taken from the water tap at different times.

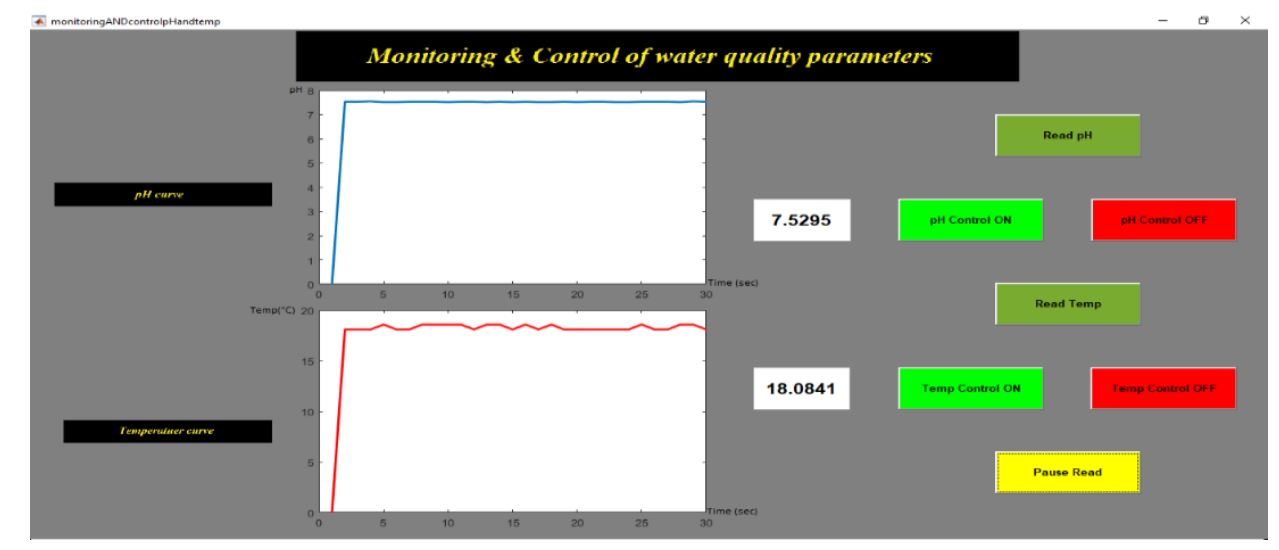

C

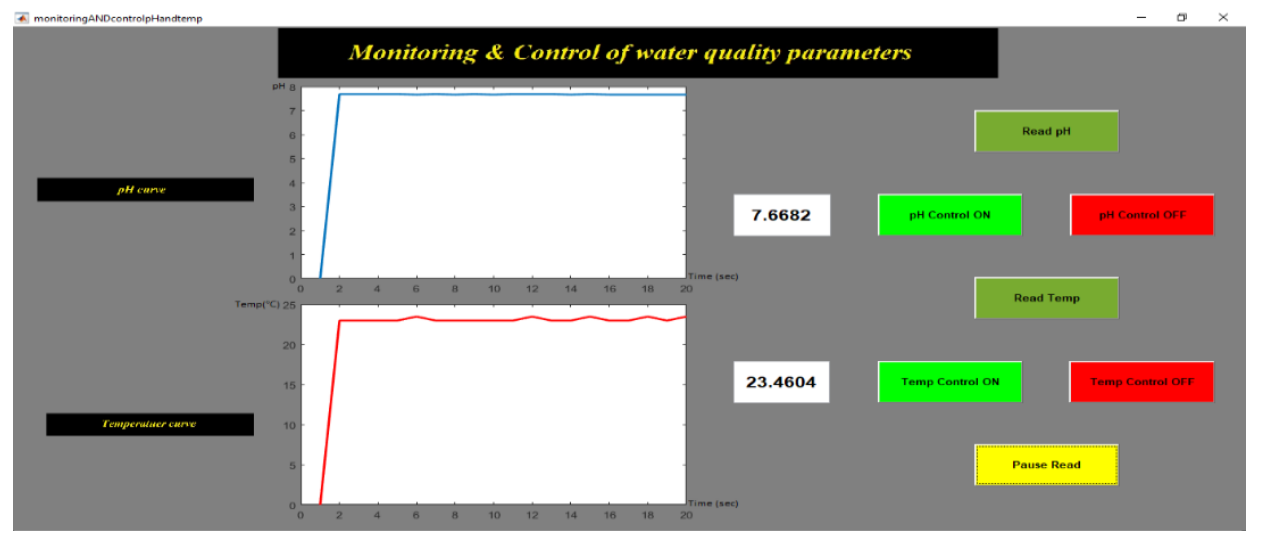

D

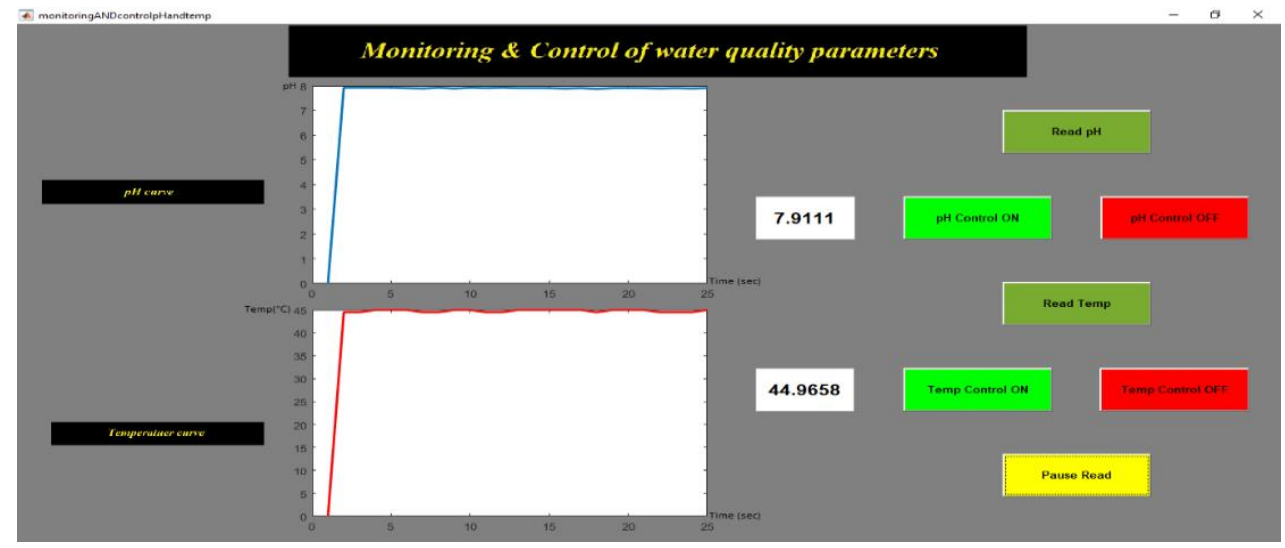

$\mathbf{E}$

Figure 20: GUI Monitoring \& control of $\mathrm{pH}$ and temperature (sample 1) 
Figure 20 gives the results of the first water sample at different temperatures. This sample was divided into three small samples: the first sample at low temperature, the second sample at normal temperature and the third sample at high temperature. Where the $\mathrm{pH}$ and temperature were measured in the three samples and through these measurements, it was found that the change in the temperature leads to a change in the value of $\mathrm{pH}$ in water.

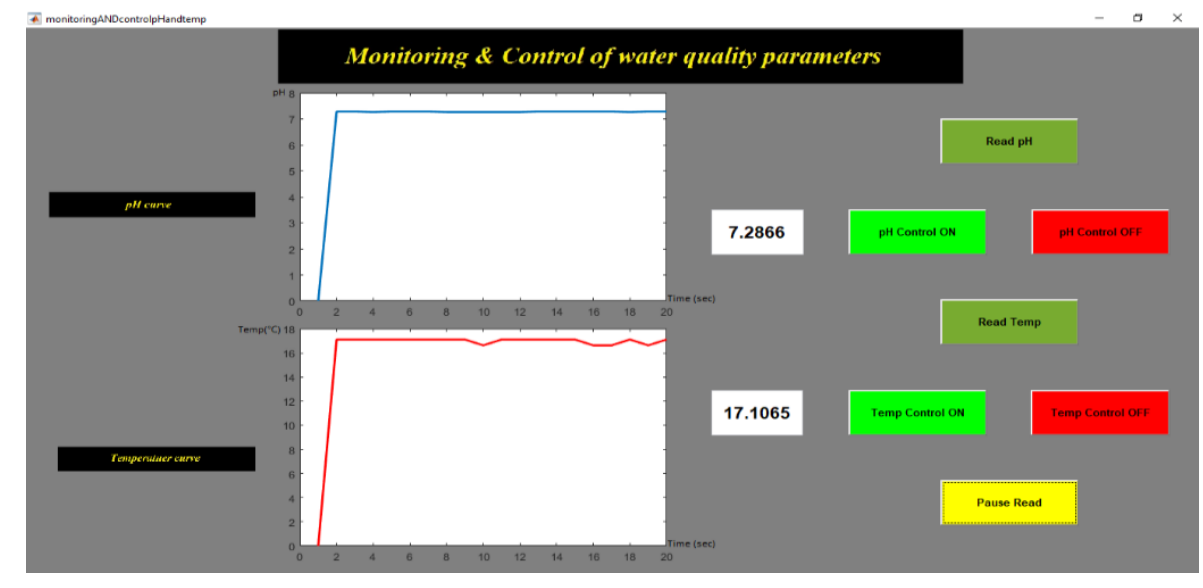

$\mathbf{F}$

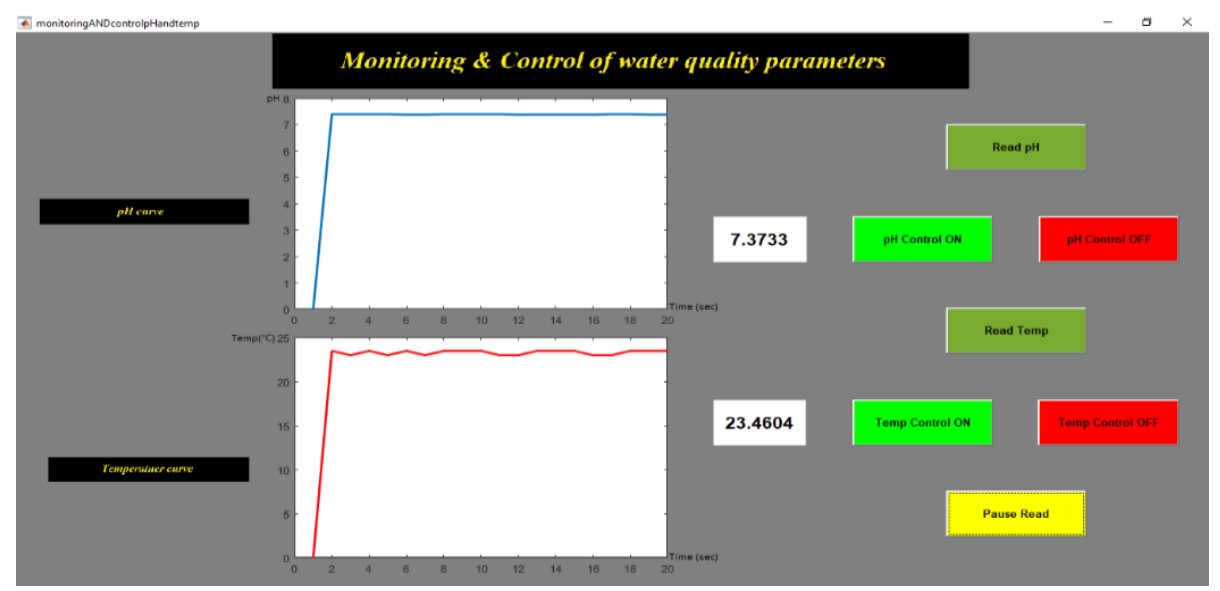

G

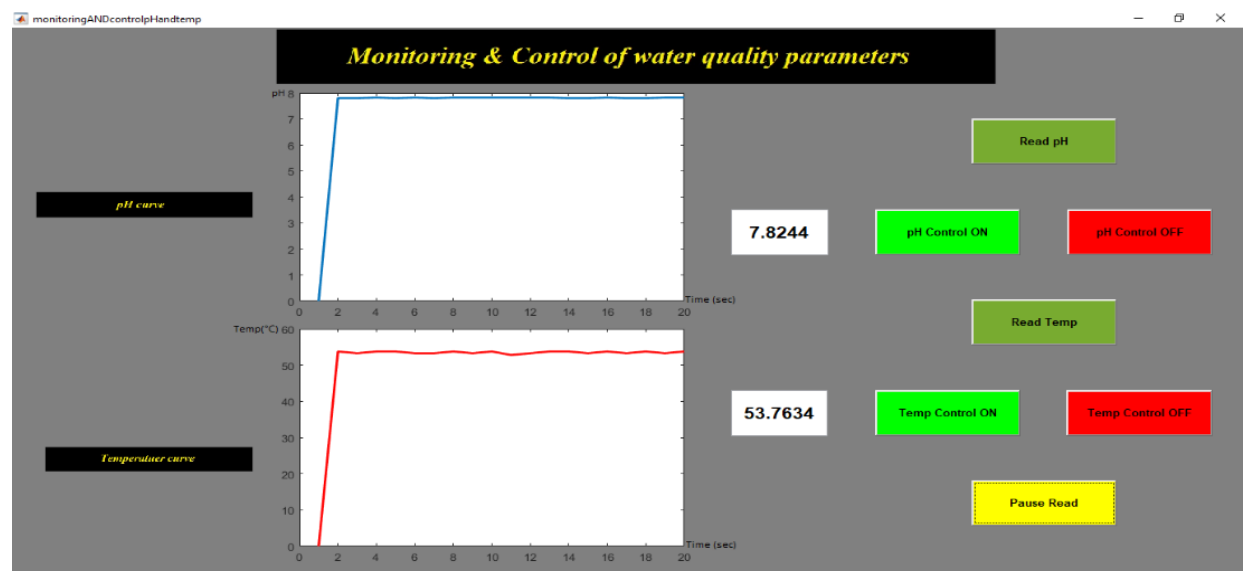

$\mathbf{H}$

Figure 21: GUI Monitoring \& control of $\mathrm{pH}$ and temperature (sample 2) 
In Figure 21, the results of second water sample at different temperatures are shown. This sample was divided into three small samples: the first sample at low temperature, the second sample at normal temperature and the third sample at high temperature. Where the $\mathrm{pH}$ and temperature were measured in the three samples and through these measurements, it was found that the change in the temperature leads to a change in the value of $\mathrm{pH}$ in water.

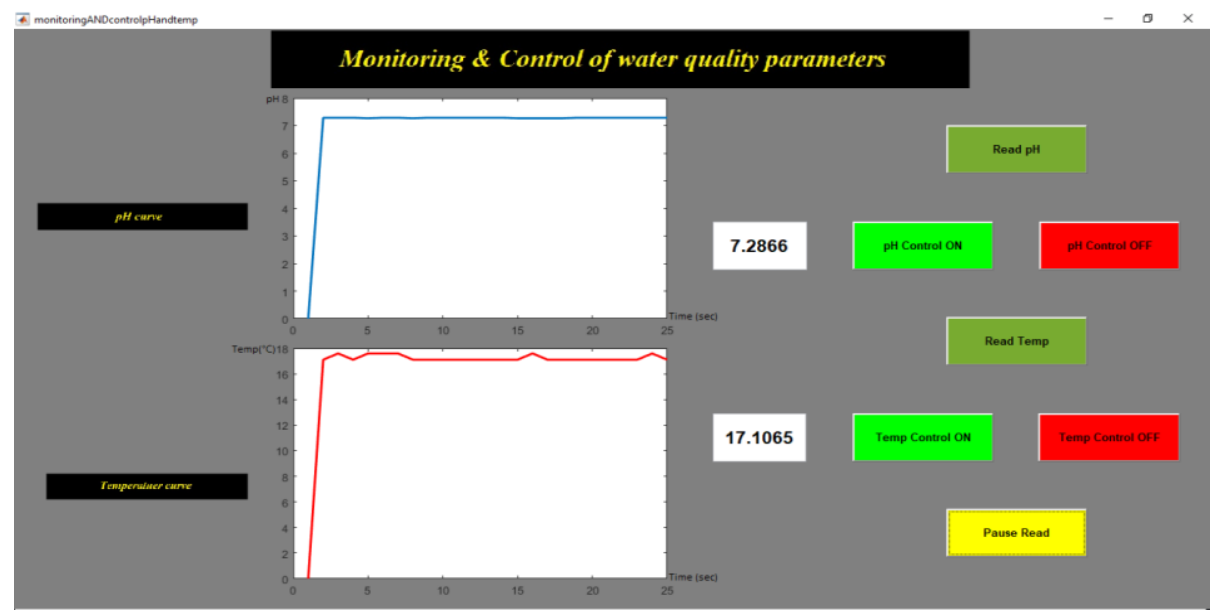

I

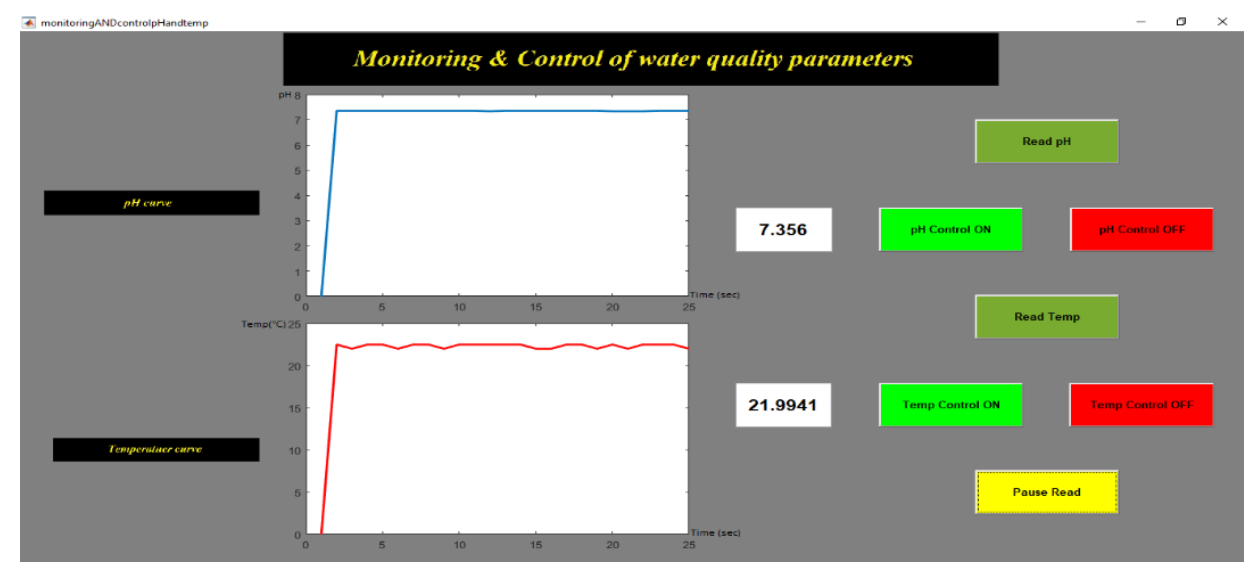

$\mathbf{K}$

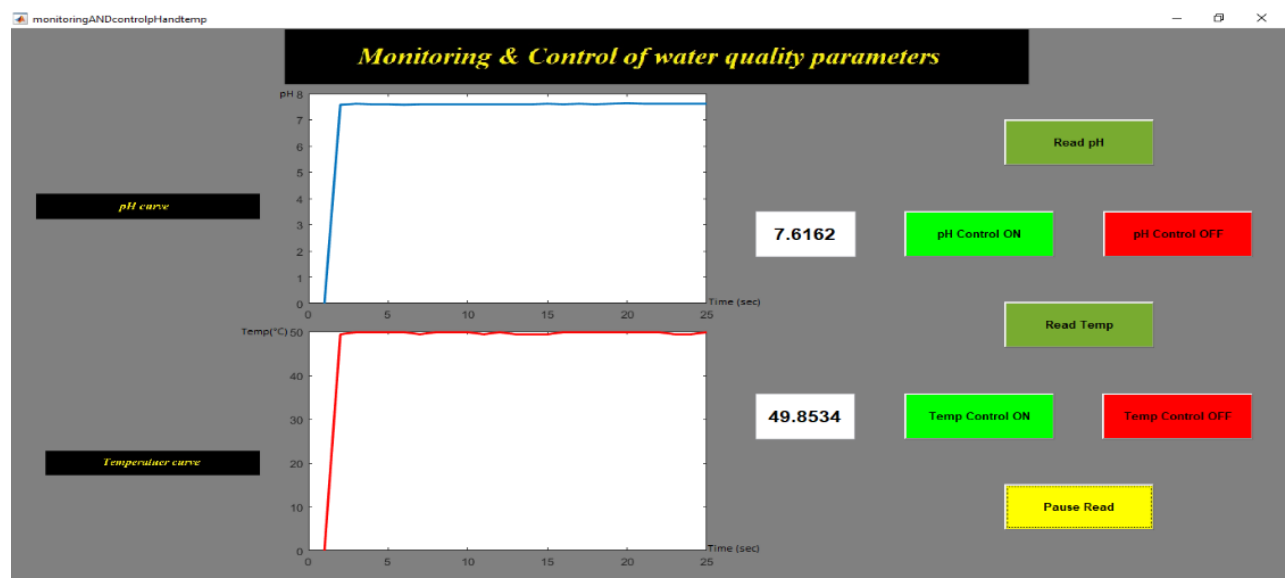

$\mathbf{L}$

Figure 22: GUI Monitoring \& control of $\mathrm{pH}$ and temperature (sample 3) 
The results of the third water sample at different temperatures are shown in Figure 22. This sample was divided into three small samples: the first sample at low temperature, the second sample at normal temperature and the third sample at high temperature. Where the $\mathrm{pH}$ and temperature were measured in the three samples and through these measurements, it was found that the change in the temperature leads to a change in the value of $\mathrm{pH}$ in water.

Table I present the results of three samples. Through looking at the table, find that the changes in the temperature value lead to changes in the $\mathrm{pH}$ value. The results show that when the temperature value increasing also the $\mathrm{pH}$ value increasing.

Table I: displays the results values for three samples of water

\begin{tabular}{|l|l|l|}
\hline \multirow{3}{*}{ Water Samples } & \multicolumn{2}{|l|}{ parameters } \\
\cline { 2 - 3 } & $\begin{array}{l}\text { Temperature } \\
{ }^{\circ} \mathbf{C}\end{array}$ & $\mathbf{p H}$ \\
\hline \multirow{3}{*}{ Sample 1 } & 18.08 & 7.52 \\
\cline { 2 - 3 } & 23.46 & 7.66 \\
\cline { 2 - 3 } & 44.96 & 7.91 \\
\hline \multirow{3}{*}{ Sample 2 } & 17.10 & 7.28 \\
\cline { 2 - 3 } & 23.46 & 7.37 \\
\cline { 2 - 3 } & 53.76 & 7.82 \\
\hline \multirow{3}{*}{ Sample 3 } & 17.10 & 7.28 \\
\cline { 2 - 3 } & 21.99 & 7.35 \\
\cline { 2 - 3 } & 49.85 & 7.61 \\
\hline
\end{tabular}

From the experimental results of these samples, it is found that the ratio of $\mathrm{pH}$ is increased when the temperature is changed, whether to a higher or lower temperature. We here indicate the importance of temperature monitoring when measuring the $\mathrm{pH}$ ratio and keeping it at a constant value so as not to affect the results of the $\mathrm{pH}$. Because many applications are need stability in the value of $\mathrm{pH}$.

\section{Conclusion}

Efficient real-time water monitoring has been presented in this research work using different parameters sensors and microcontroller. Also, Matlab program is utilized to design the GUI screen for easy monitoring and observing. Many experiments are carried out to check the presented technique efficiency. In the experimental results, the relation between the water temperature and $\mathrm{pH}$ value is studied. The experiments revealed that the proposed system is able to monitor and control quality of water parameters. Also the proposed system has many advantages such as low cost, the flexibility to measure other parameters through the addition of other sensors, and it can be used in water monitoring in different applications, whether drinking, agriculture or industry. In the near future work, this technique will be developed to interactive real-time water quality control through wireless sensor networks. 


\section{References}

[1] "Water quality control”, www.pg.gda.pl/chem/Dydaktyka/Analityczna/WQC/wqc_p2.pdf $7 / 10 / 2017$.

[2] T. Tebbutt, (2002). "Principles of Water Quality Control", Fifth Edition, Butterworth-Heinemann, An Imprint of Elsevier Science, Transferred to Digital Printing.

[3] G. Celebic, and D. IlijaRendulic, "Basic Concepts of Information and Communication Technology", Open Society for Idea Exchange, Zagreb.

[4] H. Kobayashi, Y. Hino, I. Ho, B. Pham, and S. Watanabe, (2012) "Information and Communication Technology based Tele-Monitoring for Elderly Care Houses”, International Conference on Control, Automation, Robotics \& Vision Guangzhou, China.

[5] Y. Liu, C. Yu, and X. Xiao, (2013) "Study of Wireless Safety Monitoring System for Driver Based on Information Fusion Technology", Vehicular Electronics and Safety (ICVES), international conference IEEE.

[6] Y. Jen, and S. Chang, (2016) "Information and Communication Technologies for Enhanced Emergency Management in Taiwan High Speed Rail”, Intelligent Rail Transportation (ICIRT), international conference IEEE

[7] Y. Lin, T. Chang, C. Fan , J. Anthony, J. Petway, W. Lien , C. Liang, and Y. Ho, (2017) "Applications of Information and Communication Technology for Improvements of Water and Soil Monitoring and Assessments in Agricultural Areas-A Case Study in the Taiyuan Irrigation District", Environments.

[8] L. Deshpande, "Water Quality Analysis Laboratory Methods", http://mpcb.gov.in/envtdata/LSDNEERI\%20Water\%20Quality\%20Analysis.pdf 7/10/2017 .

[9] H. Company, (2010) “What Is pH And How Is It Measured?” A Technical Handbook for Industry

[10] E. Management, (2010) "The Theory of pH Measurement", Application Data Sheet.

[11] J. Ashton, and L. Geary, (2006) "The Effects of Temperature on pH Measurement".

[12] S. Priya, J. Mani, and P. Amudha, (2014) "Monitoring and Control System for Industrial Parameters Using Can Bus", International Journal of Engineering Trends and Technology (IJETT).

[13] Ö. Çetinkaya, and H. Kuscu, (2009) "Measurement of Water Level and Temperature", International Scientific Conference

[14] D. Jain, A. Parakh, and H. Verma, (2014) "Microcontroller Based System for Water Quality Monitoring Using Electronic Sensors", International Journal of Advanced Research in Electrical, Electronics and Instrumentation Engineering.

[15] M. Pradeepkumar, J. Monisha, R. Pravenisha, V. Praiselin, and K. Devi, (2016) "The Real Time Monitoring of Water Quality in IOT Environment", International Journal of Innovative Research in Science, Engineering and Technology

[16] Srivatsava, and P. Reddy, (2016) "Design of a Water Environment Monitoring System Based on IOT Using Embedded Linux”, International Journal\& Magazine of Engineering, Technology, Management and Research

[17] Dfrobot.com, "PH Meter (SKU: SEN0161)" 27 June 2017. [Online] Available: https://www.dfrobot.com/wiki/index.php/PH_meter(SKU:_SEN0161) 1 October 2017.

[18] store.fut-electronics.com, “Temperature Sensor Waterproof". [Online] Available: https://store.futelectronics.com/collections/temperature,humidity/products/waterprooftemperature-sensor-digital, October 2017.

[19] J. Boxall. (2013) "Arduino Workshop", No starch press, San Francisco

[20] J. Nussey, (2013) “Arduino for Dummies", John Wiley \& Sons

\footnotetext{
*Corresponding author.

E-mail address: tariq. tito76 @yahoo.com
} 